\section{Profile of patients with tinea capitis}

\author{
Siti Amira Venitarani, ${ }^{1}$ \\ Samsriyaningsih Handayani, ${ }^{2}$ \\ Evy Ervianti ${ }^{3}$
}

${ }^{1}$ Faculty of Medicine, Universitas

Airlangga, Surabaya; ${ }^{2}$ Department of Public Health - Preventive Medicine, Faculty of Medicine Universitas Airlangga / Dr. Soetomo General Hospital Surabaya; ${ }^{3}$ Department of Dermatology and Venereology, Faculty of Medicine Universitas Airlangga / Dr. Soetomo General Hospital Surabaya, Indonesia

\begin{abstract}
Tinea capitis is dermatophyte infection of the scalp and hair, affecting mainly prepubertal children. Its incidence has increased over the last decades. If not diagnosed and treated properly, it might reach epidemic soon. This study was descriptive retrospective study which evaluated the incidence and profile of tinea capitis among patients of Micology Division, Outpatient Clinic of Dermatology and Venereology Department, Dr. Soetomo General Hospital Surabaya in 2014 - 2016. There were 42 tinea capitis new cases. It was most prevalent among the age group of 5-14 years old. Male was more common. The most common main complaint was itching. The most frequent predisposing factor was cat exposure. Squama was the most prevalent efflorescence. $\mathrm{KOH}$ examination data showed that $57.1 \%$ patients were arthrospore positive and $66.7 \%$ were positive in Wood lamp examination. Culture was done among 24 patients with positive result of $52.4 \%$ and Microsporum canis as the most prevalent dermatophytes. There were $33.3 \%$ patients diagnosed with grey patch type. The most common treatment was oral griseofulvin. Follow-ups were done to all patients but only $64.3 \%$ who visited back.
\end{abstract}

\section{Introduction}

Tinea capitis is characterized by dermatophytes invasion, mostly species of Trichopyton and Microsporum, into hair follicles and keratinized layer of hairy skin leading to hair loss, scaling, kerion, favus, black dot, grey patch type, erythema, or impetigo-like lesions. ${ }^{1}$ Tinea capitis is the most common dermatophytosis of the scalp affecting mainly children, aged between six months and prepubertal age, and rarely adults. Survey by Ayanlowo et al. (2013) in Nigeria revealed that tinea capitis was found in all age groups and accounted for $72.2 \%$ of fungal infections between ages 0 and 9 while the frequency of presentation reduces with the increase of age. ${ }^{2}$

The epidemiology of tinea capitis varies within different geographical areas throughout the world but is endemic to tropical regions as the growth of dermatophyte is facilitated by warm and humid climate. An increase in its incidence has been distinguished over the last few decades. ${ }^{3}$ Besides, the worldwide distribution of tinea capitis is also related to lifestyle, migration patterns, primary host range, secondary host immunity, presence of immunodeficiency disease, and patients attitude to prompt treatment following clinical presentation and standard of living. ${ }^{4}$

Several therapeutic options are available for treating tinea capitis, however griseofulvin has been the drug of choice for the past years. Still, newer antifungal agents are needed to be discovered as clinical studies over the past decades have shown decreasing sensitivity of tinea capitis to griseofulvin. ${ }^{5}$

According to WHO (2005), tinea capitis is considered as a common disorder which means that it occur frequently in the general population or at a primary or peripheral healthcare level. ${ }^{6}$ Tinea capitis also has a highly considerable psychological effects and is considered as a costly disease in terms of loss of working days and treatment due to its high morbidity. ${ }^{7}$ Therefore, it is important to discover the incidence and profile of tinea capitis in order to give benefit on prevention, diagnosis, selection of thearpy, and patient education to improve tinea capitis incidence and patients' quality of life in the future.

\section{Materials and Methods}

This research was a descriptive retrospective study. It was performed by collecting secondary data from medical records of all new patients with the diagnosis of tinea capitis in Micology Division, Outpatient Clinic of Dermatology and Venereology Department, Dr. Soetomo General Hospital Surabaya within the period of three years, $1^{\text {st }}$ of January $2014-31^{\text {st }}$ of December 2016. Data taken from the medical records were initial data (number of cases, age, sex, visiting time, and
Correspondence: Siti Amira Venitarani, Faculty of Medicine, Universitas Airlangga, J1. Mayjen. Prof. Dr. Moestopo, No. 47, Airlangga, Gubeng, Surabaya, Jawa Timur, 60286, Indoensia.

Tel.: +6282232938183

E-mail: sitiamiravenitarani@gmail.com

Key words: tinea capitis, dermatophyte, prepuberty, descriptive retrospective study.

Contributions: The authors contributed equally.

Conflict of interest: there is no conflict of interests.

Funding: This study is not sponsored.

Received for publication: 1 February 2019. Accepted for publication: 12 February 2019.

This work is licensed under a Creative Commons Attribution-NonCommercial 4.0 International License (CC BY-NC 4.0).

CC Copyright S.A. Venitarani et al., 2019

Licensee PAGEPress, Italy

Dermatology Reports 2019; 11(s1):8042 doi:10.4081/dr.2019.8042

residence) and clinical data (history taking, duration of illness, previous treatment, diagnosis, physical examination, additional examination, management, and follow-ups).

\section{Results}

There were 42 tinea capitis new cases out of 1,757 new cases in Micology Division, Outpatient Clinic of Dermatology and Venereology Department, Dr. Soetomo General Hospital Surabaya in 2014-2016. There were different number of tinea capitis new cases each year, which are 15 in 2014 , 11 in 2015, and 16 in 2016, with the average of 14 new cases. However, the percentage kept increasing from $2.3 \%$ in 2014 to $2.4 \%$ in 2015 and finally to $2.5 \%$ in 2016 .

Age group in which tinea capitis was most prevalent was 5-14 years old (69\%), followed by $1-4$ years old $(28.6 \%)$, and 15 24 years $(2.4 \%)$. Male patients $(59.5 \%)$ was higher than female patients $(40.5 \%)$. The number of patients from Surabaya $(73.8 \%)$ was higher than patients from outside Surabaya $(26.2 \%)$ with the difference of 20 patients.

From history taking data, distribution of main complaint, duration of illness, previous treatment, and risk factor could be discovered. Patient's main complaint were mostly itching $(83.3 \%)$, hair loss $(59.5 \%)$, 
and baldness $(40.5 \%)$. Other main complaint found among patients were scaling (31\%), reddish spot $(31 \%)$, whitish spot $(16.7 \%)$, grayish spot $(11.9 \%)$, pain (2.4\%), pus (2.4\%), lump (2.4\%), and crust $(2.4 \%)$. Patients' duration of illness were 16 months $(57.2 \%)$ or $<1$ month $(42.8 \%)$.

Usually, patients did not receive any treatment before (19\%). Some of them used unknown oral drug $(14.3 \%)$ or unknown cream (11.9\%). Other patients used ketoconazole $(9.5 \%)$, minyak tawon $(9.5 \%)$, cetirizine $(7.1 \%)$, griseofulvin $(4.8 \%)$, corticosteroid topical (4.8\%), cefadroxil (4.8\%), hair tonic $(2.4 \%)$, alcohol $(2.4 \%)$, baby oil (2.4\%), Salep 88 (2.4\%), kalpanax (2.4\%), methylprednisolone (2.4\%), inerson cream $(2.4 \%)$, mupirocin cream $(2.4 \%)$, gentamycin topical (2.4\%), Salep Pi kang shuang $(2.4 \%)$, miconazole $(2.4 \%)$, or erythromycin $(2.4 \%)$ before coming to the clinic.

The distribution of risk factor among patients could be seen in Table 1. Physical examination data revealed squama $(85.7 \%)$ as the most prevalent efflorescence, followed by erytematous macule (31\%), hypopigmentation $(14.3 \%)$, and papule (11.9\%). Besides, 9.5\% patients were found with hyperpigmentation, $7.1 \%$ with erosion, $4.8 \%$ with grayish macule, $4.8 \%$ with pustule, $2.4 \%$ with nodule, $2.4 \%$ with crust.

Additional examination included $\mathrm{KOH}$ laboratory examination and Wood lamp examination. The distribution of $\mathrm{KOH}$ laboratory examination result could be seen in Table 2. On the other hand, it is found that $66.7 \%$ patients were positive in Wood lamp examination and $21.4 \%$ were tested negative. Culture was done among 24 patients with positive result of $52.4 \%$ and negative result of $4.8 \%$. Microsporum canis $(54.2 \%)$ was the most prevalent dermatophyte found in the culture examination result, followed by no growth (25\%), Microsporum audouinii (12.5\%), and Tricophyton mentagrophytes (8.3\%). Most frequently, there was no data $(45.3 \%)$ regarding the type of tinea capitis. However, 33.3\% were diagnosed with grey patch type tinea capitis, $11.9 \%$ with kerion type, and $9.5 \%$ with black dot type.

Most of the patients were treated with oral griseofulvin $(90.5 \%)$. Some of them also treated with ketoconazole $2 \%$ shampoo $(33.3 \%)$, cetirizine $(4.8 \%)$, erythromycin (4.8\%), selenium sulfide $2 \%$ shampoo (2.4\%), hidrocortisone $2.5 \%$ cream $(2.4 \%)$, urea $10 \%$ cream $(2.4 \%)$, and miconazole $2 \%$ cream (2.4\%). Education for follow-up was done to all patients but only 27 (64.3\%) patients who visited back for follow-ups.

\section{Discussion}

There were decreasing number of new cases from 2014 to 2015 but increasing number from 2015 to 2016 in Micology Division, Outpatient Clinic of Dermatology and Venereology Department, Dr. Soetomo General Hospital Surabaya. This could possibly be caused by the starting operation of Badan Penyelenggara Jaminan Sosial Kesehatan (BPJS Kesehatan), which is a national health insurance organization in Indonesia, in 2015. Since then, Dr. Soetomo General Hospital Surabaya has been categorized as the third level health care facility. Therefore, patients who come must bring referral letters from the lower level health care facility. ${ }^{8}$

Age group in which tinea capitis was most prevalent was 5-14 years $(69 \%)$. This result is supported by a study in RSUPN dr. Cipto Mangunkusumo, Jakarta, in 20052010 which revealed that tinea capitis generally occurs in patients with the age group $\leq 14$ years old $(73.91 \%) .{ }^{9}$ Tinea capitis patients are mostly found in prepubertal age because the quantity of fungistatic saturated fatty acids in sebum increases at puberty. Other than that, Pityrosporum orbiculare colonisation in puberty age may intrude dermatophyte colonisation. Thicker hair will also protect against dermatophytic invasion. Hence, in adults, this disease is mostly found among immunosuppressed and HIVinfected patients only. ${ }^{10}$

A study by Aprilia et al. among elementary school students in Jatinangor, Sumedang, West Java reported that 194 $(49.6 \%)$ patients were boys and 197 (50.4\%) patients were girls which showed no significant difference in tinea capitis' patient gender. ${ }^{11}$ However, there were 25 $(59.5 \%)$ male patients and $17(40.5 \%)$ female patients with the diagnosis of tinea capitis in Dr. Soetomo General Hospital Surabaya. The higher number of male patients is assumed to be caused by lower level of progesterone, which cause steroidmediated inhibition of dermatophyte growth, and fungistatic sebum in male. ${ }^{12}$ Patients who came from Surabaya (73.8\%) were higher than from outside Surabaya such as Sidoarjo and Madura might be because people tend to find the nearest help first to treat their illnesses. ${ }^{9}$

It is found that itching was the most prevalent main complaint, followed by hair loss and baldness. It is supported by a study by Ayanlowo et al. in Nigeria which report-

Table 1. Risk factor distribution of patients with the diagnosis of tinea capitis in Micology Division, Outpatient Clinic of Dermatology and Venereology Department, Dr. Soetomo General Hospital Surabaya in 2014-2016.

\begin{tabular}{lcccc} 
Risk factor & \multicolumn{4}{c}{ Year } \\
& $\begin{array}{c}2014(\%) \\
\mathrm{n}=15\end{array}$ & $\begin{array}{c}2015(\%) \\
\mathrm{n}=11\end{array}$ & $\begin{array}{c}2016(\%) \\
\mathrm{n}=16\end{array}$ & $\mathrm{n}=42$ \\
Cat exposure & $12(80)$ & $9(81.8)$ & $8(50)$ & $29(69)$ \\
Bird exposure & 0 & 0 & $2(12.5)$ & $2(4.8)$ \\
\hline Playing with sand & $1(6.7)$ & 0 & 0 & $1(2.4)$ \\
Sleeping on the floor & $2(13.3)$ & 0 & 0 & $2(4.8)$ \\
\hline Down syndrome patient & 0 & 0 & $1(6.3)$ & $1(2.4)$ \\
Post hospitalization & 0 & $1(6.7)$ & $1(6.3)$ & $2(4.8)$ \\
\hline Public baths & 0 & $1(6.7)$ & 0 & $1(2.4)$ \\
No data & $2(13.3)$ & $1(6.7)$ & $4(25)$ & $7(16.7)$ \\
\hline
\end{tabular}

Table 2. KOH laboratory examination result distribution of patients with the diagnosis of tinea capitis in Micology Division, Outpatient Clinic of Dermatology and Venereology Department, Dr. Soetomo General Hospital Surabaya in 2014-2016.

\begin{tabular}{lcccc} 
KOH laboratory & \multicolumn{3}{c}{ Year } \\
examination & $\begin{array}{c}2014(\%) \\
\mathrm{n}=15\end{array}$ & $\begin{array}{c}2015(\%) \\
\mathrm{n}=11\end{array}$ & $\begin{array}{c}2016(\%) \\
\mathrm{n}=16\end{array}$ & $\mathrm{n}=42$ \\
Hyphae positive & $5(33.3)$ & $7(63.6)$ & $8(50)$ & $20(47.6)$ \\
Arthrospore positive & $11(73.3)$ & $7(63.6)$ & $6(37.5)$ & $24(57.1)$ \\
\hline Hyphae + arthrospore positive & $4(26.7)$ & $5(45.5)$ & $2(12.5)$ & $11(26.2)$ \\
Negative & $2(13.3)$ & $2(18.2)$ & $4(25)$ & $8(19)$ \\
\hline No data & $1(6.7)$ & 0 & 0 & $1(2.4)$ \\
\hline
\end{tabular}


ed itching as the most prevalent associated symptoms among respondents. ${ }^{2}$ Tinea capitis clinical presentation is commonly a single or multiple patches of hair loss, which may be accompanied by inflammation, scaling, pustules, and itching. ${ }^{1}$

The most common predisposing factor which is reported in this study is associated with cat, while other factors could be seen in Table 1. A prevalence study in SouthWest Nigeria confirmed keeping or playing with pets and having contact with foreign object as one of tinea capitis predisposing factors. ${ }^{13}$ Having contact with pets and wild animals was also reported among 9 $(39.13 \%)$ patients in a study by Sari et al. in RSUPN Dr. Cipto Mangunkusumo Jakarta. ${ }^{9}$ A person could be infected by zoophilic organism through contact with pets or wild animals. Cats and dogs are main sources of Microsporum canis, while contact with soil is the main source of Microsporum gypseum. In this study, $69 \%$ patients came with history of contact with cat which may be Microsporum canis source of infection. ${ }^{14}$ This assumption is supported by culture positive results data which shows that Microsporum canis was the most prevalent (54.2\%) dermatophytes among patiens.

Beside culture, other additional examinations which were usually done are $\mathrm{KOH}$ and Wood lamp examination. From Table 2, it is known that $78.6 \%$ tinea capitis patients had positive $\mathrm{KOH}$ examination result. Arthrospore is asexual spore formed by the fragmentation of pre-existing hyphae. This means that hyphae positive $\mathrm{KOH}$ examination result shows acute infection and arthrospore positive shows chronic infection of tinea capitis. While hyphae + arthrospore positive result shows more chronic infection. ${ }^{15}$

Whereas, in Wood lamp examination, there were $66.7 \%$ patients with positive results. Positive fluorescence of Wood lamp examination could be found in Microsporum canis, Microsporum audouinii, Microsporum distortum, Microsporum ferrugineum, and sometimes Trichophyton schoenleinii. Wood lamp examination will especially show positive result in ectothrix dermatophytes. ${ }^{15}$ This also supports that $33.3 \%$ of tinea capitis patients in Dr. Soetomo General Hospital Surabaya suffered from grey patch type tinea capitis.

Gold standard for tinea capitis treatment is oral griseofulvin because it shows the best effectiveness for Microsporum sp. and sensitive towards dermatophytes. ${ }^{6}$ In Dr. Soetomo General Hospital Surabaya, 90.5\% of tinea capitis patients were given oral griseofulvin. On the other hand, ketoconazole $2 \%$ shampoo which has a broader spectrum, is used as adjuvant treatment and erythromycin is used to prevent second infection in tinea capitis infection. ${ }^{14}$

Education for follow-ups were done to all patients. However, patients who visited back for follow-ups were only 27 (64.3\%) of 42 patients. Noncompliance could be caused by several factors such as low education given from the medical practitioners, patient's low understanding level of the importance of follow-ups, and residence which is far from the hospital. ${ }^{9}$

\section{Conclusions}

The research results conclude that tinea capitis cases increased every year in percentage and should be put in attention. It is also found that tinea capitis was more frequent in male children. Most common main complaint and predisposing factor were itching and cat exposure. From examination, it was more frequently found that patient had efflorescence of squama, arthrospore positive $\mathrm{KOH}$ examination, positive Wood lamp examination, and Microsporum canis positive culture examination. Grey patch type tinea capitis was most common. Patients were treated with oral griseofulvin and always given education for follow-ups, however not all visited back. The incidence and profile of tinea capitis evaluated in this study could give benefit on prevention, diagnosis, selection of therapy, as well as patient education. Therefore, the number of incidence and quality of life of tinea capitis patients could be improved.

\section{References}

1. Guerrant R, Walker D, Weller P. Tropical infectious diseases: Principles, Pathogens and Practice. 3rd ed. Philadelphia: Churchill Livingstone, Elsevier; 2011.

2. Ayanlowo O. Dermatophyte infections at the Dermatology Outpatients' Clinic of the Lagos University Teaching Hospital. Nig Qt J Hosp Med 2013; 23:1-6.

3. Ginter-Hanselmayer G, Weger W, Ilkit M, Smolle J. Epidemiology of tinea capitis in Europe: current state and changing patterns. Mycoses 2007; 50(s2):6-13.

4. Nelson MM, Martin AG, Heffernan MP. Superficial fungal infections: dermatophytosis, onychomycosis, tinea nigra, piedra. In: Freedberg IM, Eisen AZ, Wolff K, Austen KF, Goldsmith LA, Katz SI, editors. Fitzpatrick's dermatology in general medicine. 6th ed. New York: McGraw-Hill; 2003. p. 1989-2005.

5. Dastghaib L, Azizzadeh M, Jafari P. Therapeutic options for the treatment of tinea capitis: Griseofulvin versus fluconazole. J Dermatolog Treat 2005;16(1):43-46.

6. WHO. Epidemiology and Management of Common Skin Diseases in Children in Developing Countries. Geneva: WHO; 2005.

7. Teklebirhan GBitew A. Prevalence of Dermatophytic Infection and the Spectrum of Dermatophytes in Patients Attending a Tertiary Hospital in Addis Ababa, Ethiopia. Int J Microbiol 2015; 2015:1-5.

8. BPJS Kesehatan. Sejarah Perjalanan Jaminan Sosisal di Indonesia [Internet]. Jakarta: Badan Penyelenggara Jaminan Sosial Kesehatan; 2013 Dec [cited 2017 Jun 5]. Available from: https://bpjskesehatan.go.id/bpjs/index.php/pages/d etail/2013/4.

9. Sari A, Widaty S, Bramono K, Miranda E, Ganjardani M. Tinea kapitis di Poliklinik Kulit dan Kelamin RSUPN Dr Cipto Mangunkusumo Jakarta Periode Tahun 2005 - 2010. MDVI 2011;39(3):113-7.

10. Buckley D. Lesson of the week: Tinea capitis in adults. BMJ. 2000;320(7246):1389-90.

11. Aprilia D, Ramali L, Sadeli R. Tinea Capitis among Elementary School Students in Jatinangor,Sumedang, West Java. AMJ. 2016;3(3):340-4.

12. Emele F, Oyeka C. Tinea capitis among primary school children in Anambra state of Nigeria. Mycoses. 2008; 51( 6):536-41.

13. Dogo J, Afegbua S, Dung E. Prevalence of Tinea Capitis among School Children in Nok Community of Kaduna State, Nigeria. Journal of Pathogens. 2016;2016:1-6.

14. Mohrenschlager M, Seidl HP, Ring J, Abeck D. Pediatric tinea capitis recognition and management. Am J Clin Dermatol. 2005; 5: 203-13.

15. Grimalt R. Management of tinea capitis in childhood. Clin Cosmet Investig Dermatol 2010:89. 